\title{
CALCIUM METABOLISM IN NEPHROSIS. I. A DESCRIPTION OF AN ABNORMALITY IN CALCIUM METABOLISM IN CHILDREN WITH NEPHROSIS
}

\author{
By KENDALL EMERSON, JR. AND WILLIAM W. BECKMAN \\ (From the Hospital of The Rockefeller Institute for Medical Research, New York City)
}

(Received for publication January 8, 1945)

In 1923, not many years after Epstein's (1) original characterization of lipoid nephrosis, Salvesen and Linder (2) first observed a lowering of the serum calcium concentration which paralleled the decrease in serum protein level in patients with this disease. ${ }^{1}$ In addition, two other features indicating a disturbance of calcium metabolism in nephrosis have been described. Boyd, Courtney, and MacLachan in 1926 (5) and Scriver in 1928 (6) both noted an excessive loss of calcium in the feces and a diminished excretion in the urine.

In the course of a systematic study of children with nephrosis in this hospital over the past 5 years, a further indication of abnormal calcium metabolism has come to our attention, namely, a generalized decalcification of the skeleton as observed by $x$-ray. The degree of this decalcification varies roughly with the severity and duration of the disease; in 2 instances in our experience, fractures have occurred after relatively slight trauma. Some degree of decalcification is often demonstrable within a month after detection of the disease.

The studies reported in this and a subsequent paper were designed to correlate the $\mathrm{x}$-ray changes

1 These authors, accepting the theory that part of the serum calcium is bound to the proteins and thereby rendered non-ionizable and non-diffusable, came to the conclusion that the deficiency in the serum calcium was entirely in this fraction, and that the ionized or diffusible portion was at a normal concentration. They based their conclusion on the facts that tetany never occurred in these patients, even when the total serum calcium level fell to "tetanic" levels, and that edema fluid contained as high a concentration of calcium in nephrotic patients as in cardiac patients who had a normal serum calcium level. Since then, Liu (3) has shown by ultrafiltration that the diffusible calcium in the serum of these subjects is within normal limits, and McLean and Hastings (4) with the frog-heart technique have demonstrated that the ionized calcium is also normal. in the bones with the alterations in calcium metabolism.

\section{SUBJECTS}

Two boys, S. G. aged 11 years, and R. M. aged 4 years, and one girl, R. Q. aged 9 years, all exhibiting the signs and symptoms of the nephrotic syndrome or lipoid nephrosis were selected for study. Protocols of the subjects are shown graphically in Figure 1. Each patient had been observed in this hospital for at least 2 years prior to the period of this investigation, which was carried out during the last 6 months shown in the graphic protocols.

Subject S. G., a few months prior to this study, had begin to exhibit diminution of both the urea clearance test and the ability to concentrate the urine. In subjects R. M. and R. Q., these functions were normal. Throughout the 6-month period of study, the condition of R. Q. and S. G. remained stationary, but in the second month, R. M. underwent a spontaneous remission from his disease following a pneumococcus Type IV bacteriemia. It was possible to maintain the constant metabolic regimen throughout the recovery period. During his subsequent convalescence, he was occasionally utilized as a control, designated as "convalescent," showing a normal calcium metabolism and at the same time a degree of skeletal calcium deficiency comparable to that of the other patients. Another boy, J. P., , aged 5 years, who had recovered from an attack of acute glomerulonephritis 2 months previously, was also used as a control, designated "normal" (see Figure 1).

\section{METHOD OF STUDY}

Each subject was placed on a high-protein, low-sodium diet of constant weekly composition, adequate in calories and having a slightly alkaline ash. Vitamins were supplied by 15 drops of percomorph oil, $100 \mathrm{ml}$. of orange juice, and 10 grams of brewers' yeast daily. The dietary calcium, 75 per cent of which was in the form of milk, 


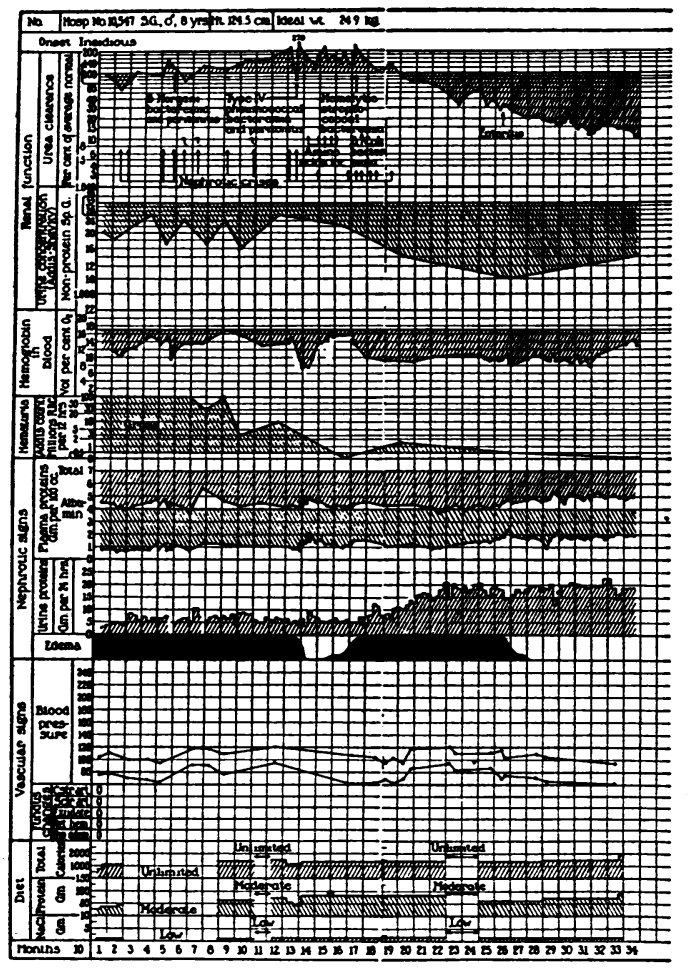

FIG. 1A

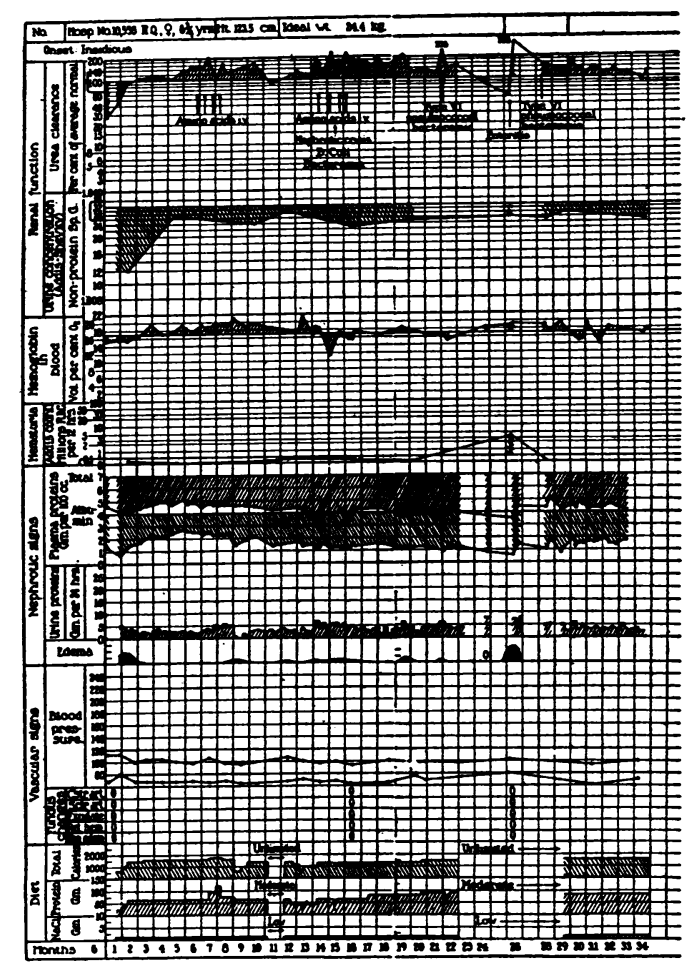

FIg. 1B

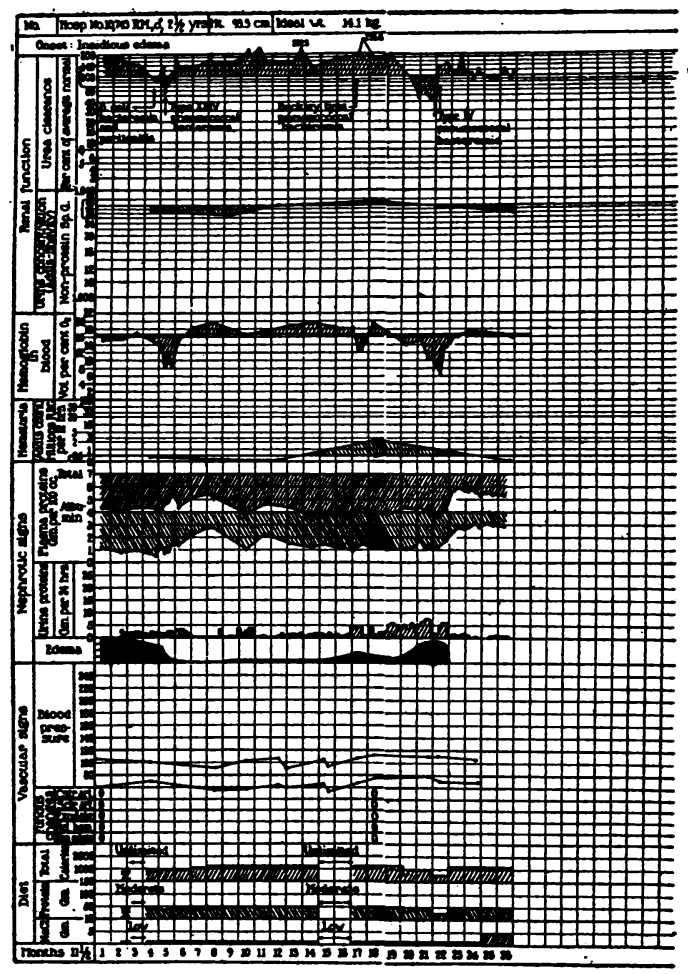

Fig. 1C

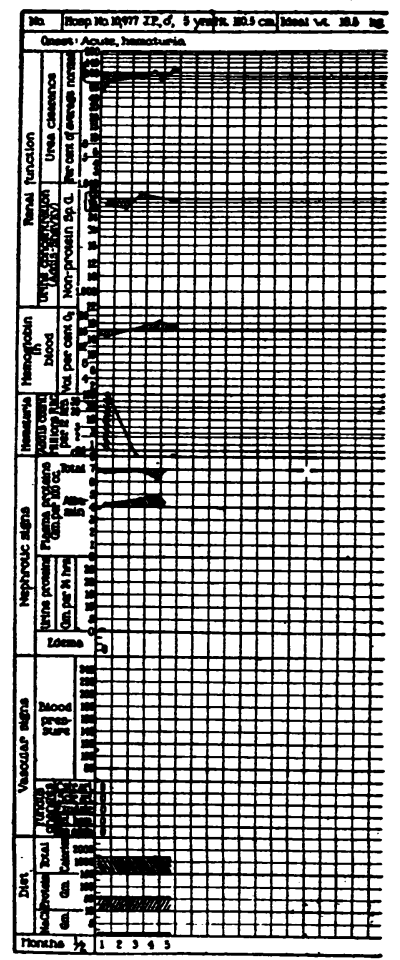

Fig. 1D

Fig. 1. Data Summarizing Laboratory and Clinical Observations on S. G., R. Q., and R. M. Throughout the ObServed Course of Their Illness

The present studies were carried out during the last 6 months shown in the figures. The fourth protocol is that of the normal control (J. P.). 
varied between 0.7 and 1 gram, and the phosphorus between 0.9 and 1.3 grams daily. After preliminary control studies, patient S. G. received 1 gram of added calcium in his diet as calcium lactate.

\section{COLLECTION OF SPECIMENS}

One-half portions of each diet as served were weighed, mixed in a Waring blender, transferred to a large evaporating dish and evaporated to dryness on a steam bath to a constant weight. The dry material was pulverized with a mortar and pestle. Duplicate 1-gram samples were weighed out for nitrogen analysis. The nitrogen content of the diets prepared for analysis in this manner never varied more than 1 per cent from the value calculated from standard tables of food analysis. Four-gram samples were used for dry ashing, which was carried out overnight in a muffle furnace at $500^{\circ} \mathrm{C}$. The ash was dissolved in hot normal $\mathrm{HCl}$, transferred quantitatively to a $100 \mathrm{ml}$. volumetric flask, cooled, made up to volume, and filtered through ash-free filter paper. Analyses for $\mathrm{Ca}, \mathrm{P}, \mathrm{Na}, \mathrm{K}$, and $\mathrm{Mg}$ were performed on the filtrate.

The stools were marked off with 0.4 gram of carmine given at the beginning of each experimental period. Each stool was transferred quantitatively from the container into which it was passed to a Waring blender. After thorough blending, the stool was again transferred quantitatively to a 5 liter bottle, previously weighed to 0.1 gram. At the end of the collection period, the bottle was again weighed to within 0.1 gram, the difference between the two weights being the wet weight of the stool plus the water used in transfer. It was then shaken for 15 minutes on a shaking machine and $10 \mathrm{ml}$. samples measured in quadruplicate into weighing bottles from a calibrated wide-mouthed pipette, allowing 5 minutes for the pipette to drain. These samples were weighed and then dried on a steam bath to a constant weight. The total dry weight of the stool was then calculated by multiplying the total wet weight by the dry weight/wet weight ratio.

The remainder of the stool was dried on a steam bath and pulverized with a mortar and pestle. The total dry weight for each metabolic period was calculated from the total wet weight $\times$ the dry weight/wet weight ratio. Duplicate 2-gram samples were ashed and dissolved in $100 \mathrm{ml}$. of normal $\mathrm{HCl}$ using the technique described above for the diets. Mineral analysis of the duplicate ash solution agreed within 1 per cent.

The urine for each metabolic period was pooled, the volume measured, and chloride and nitrogen measurements made. For other analyses, $400 \mathrm{ml}$. of urine were brought to dryness on a steam bath, ashed, and redissolved in $100 \mathrm{ml}$. normal $\mathrm{HCl}$ with the technique used for diet and stools.

\section{ANALYTICAL METHODS}

Calcium was determined on $10 \mathrm{ml}$. of urine ash $(40 \mathrm{ml}$. of urine) and $2 \mathrm{ml}$. of stool ash solution according to the procedure of Tisdall and Kramer (7). Because of the extremely low urinary calcium excretion, some samples were checked by isolating and analyzing all the calcium in $200 \mathrm{ml}$. urine samples. Similar values were obtained in both cases. Serum calcium was measured by the manometric method of Van Slyke and Sendroy (8). Magnesium was determined on $3 \mathrm{ml}$. samples of the calciumfree supernatants by the hydroxyquinolate method as outlined by Nordbö (9). Sodium was determined by the method of Butler and Tuthill (10). Only a few stool sodiums were done because the values were so low as to be negligible. Nitrogen was determined in stools and urine by the macro-Kjeldahl procedure (11). Plasma albumin and globulin were measured by the microKjeldahl method (11). Phosphorus was measured by the Fiske and Subbarow (12) method, and potassium by the method of Fiske and Litarczek (13).

For the determination of fecal lipids, two 1-gram samples of dried stool were placed in $200 \mathrm{ml}$. volumetric flasks; one sample was used for estimation of neutral fat and the other was acidified with $1 \mathrm{ml}$. of concentrated $\mathrm{HCl}$ for the analysis of total fecal lipids. The volume of each sample was increased to $200 \mathrm{ml}$. with equal parts of redistilled absolute alcohol and ether and extraction allowed to proceed for 2 hours at room temperature with occasional gentle shaking. After filtering, an aliquot of the filtrate was evaporated to dryness on a steam bath and analyzed for carbon according to the technique of Van Slyke and Folch (14) by wet combustion and manometric measurement of the $\mathrm{CO}_{2}$ produced.

\section{X-ray}

The nature of the bone changes seen in nephrosis is brought out by the contrast between the roentgenogram of the hand of a child with nephrosis and that of a normal child of similar age and development which were photographed simultaneously on the same plate (Figure 2). In the patient (No. 2), the carpals and the shafts of the phalanges, metacarpals, radius, and ulna exhibit a diffuse rarefaction, notwithstanding the fact that the epiphyseal lines are as dense as those of the normal subject. This picture suggests that, although epiphyseal growth and calcification proceed normally, for some reason there is an excessive loss of calcium from the shafts of the bones. In other words, in contrast to rickets, the difficulty in nephrosis appears not to be an inability to deposit calcium in the osteoid matrix formed at the epiphysis, but rather an inability to hold the calcium in the shafts of the bones despite adequate calcification of the epiphyseal matrix. The majority of the children with nephrosis studied in this clinic have grown at a normal rate during their illness and not one has shown any 


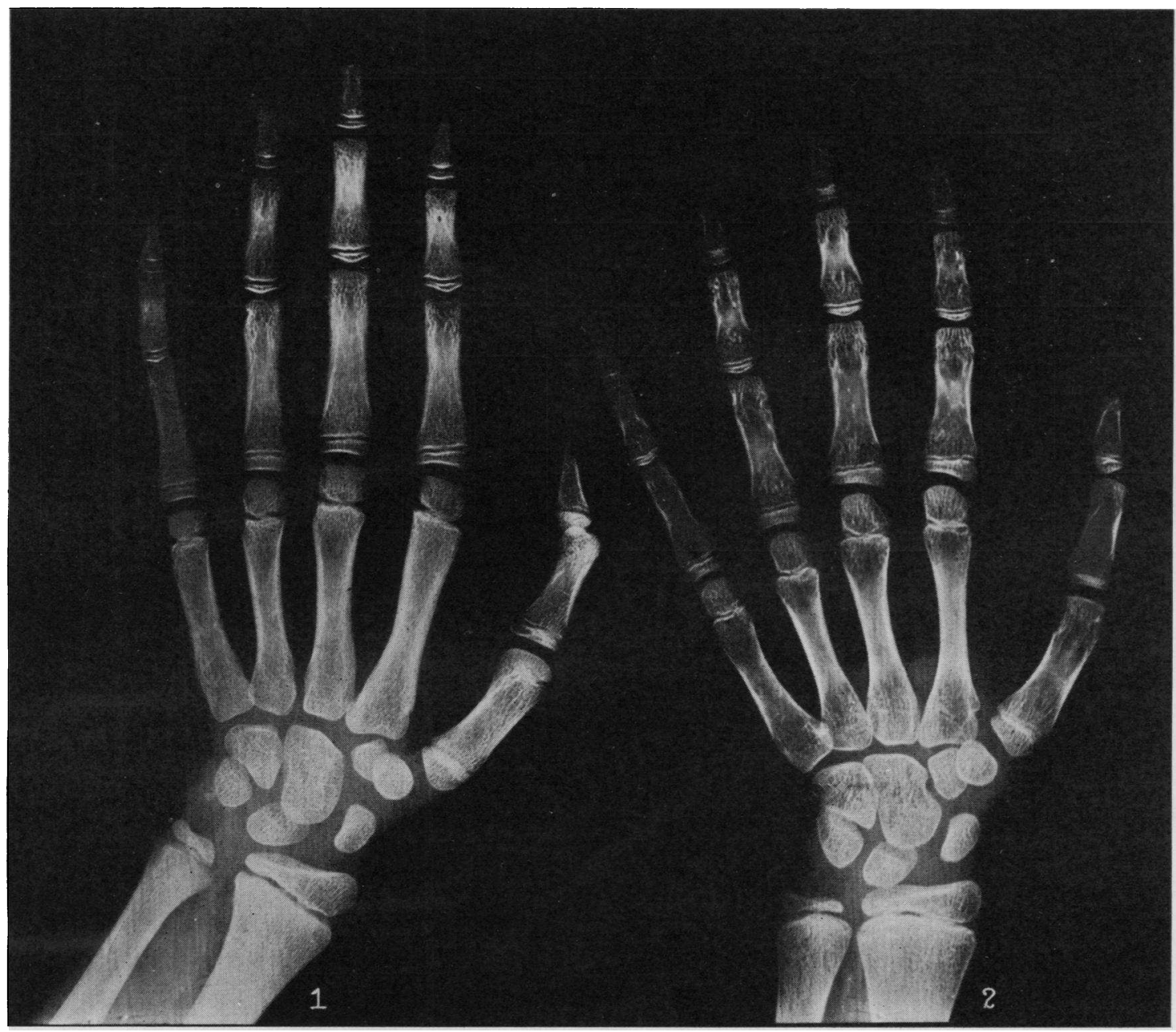

Fig. 2. X-Ray Comparison of the Hand of a Nephrotic Child (S. G., No. 2) with the Hand of a Normal Child (No. 1) of Similar Age and Development, Photographed Simultaneously on the Same Plate

sign of rickets or other skeletal disease. Even when fractures occurred, healing proceeded normally.

\section{Metabolic studies}

The metabolic data obtained on the 3 patients, which are summarized in Table $I$ along with those of the normal control, confirm the findings of previous workers $(2,5,6)$. The virtual absence of calcium from the urine is perhaps the most striking observation. We have analyzed 24hour urine specimens of 6 other patients with this disease, not included in this report, and in all obtained urinary calcium values of similar small magnitude.
Our patients showed the characteristic low serum calcium concentration common to the disease. With the exception of S. G., who had signs of renal functional insufficiency, usually accompanied by phosphorus retention, the concentration of phosphorus in the serum was normal for children of this age. It should also be mentioned that all these patients had normal levels of serum phosphatase. $^{2}$

The fecal calcium was only a little less than the calcium intake, resulting in extremely low calcium retentions. It is worthy of note that in none of

$2 \mathrm{We}$ are grateful to Dr. Fuller Albright, Massachusetts General Hospital, Boston, Massachusetts, for these measurements. 
TABLE I

Average daily nitrogen, calcium, and phosphorus balances in children with nephrosis

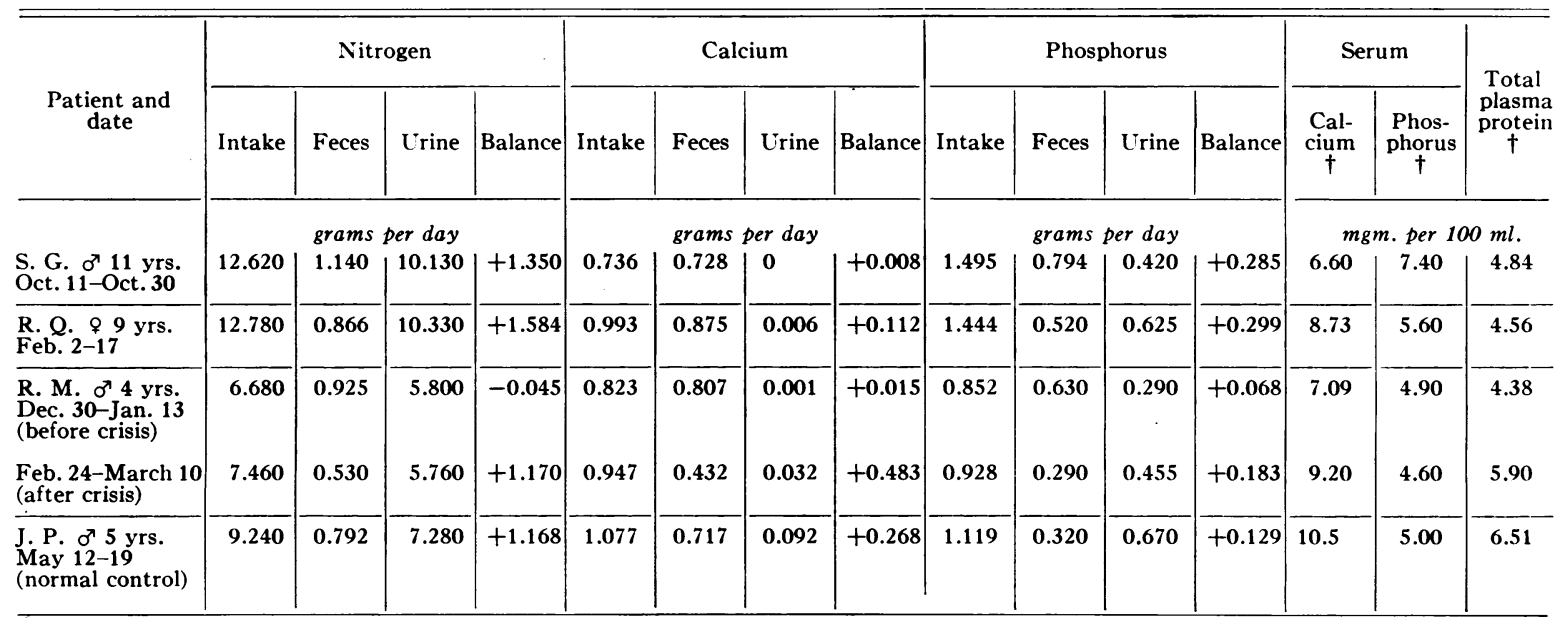

$\dagger$ Average of weekly analyses.

our patients was the excessive fecal calcium excretion associated with steatorrhea. The amount of fat in the stools was within the normal range and of the same magnitude as that in the control subject.

The fact that disturbances in nitrogen and mineral metabolism are a definite part of the nephrotic syndrome is well illustrated by the data obtained on patient R. M. before and after a "nephrotic crisis" (15) associated with a Type IV pneumococcus bacteriemia which was followed by a remission from his disease. The metabolic events which occurred at the time of the "crisis" are described by the data shown graphically in Figure 3, and they provide a striking account of a remission in nephrosis. Prior to the "crisis," the patient was extremely edematous. He had the characteristic hypoproteinemia and hypocalcemia of nephrosis. The urinary excretion of sodium averaged less than 2 m.eq. and of calcium no more than $1 \mathrm{mgm}$. daily. On the other hand, the fecal loss of nitrogen, calcium, and phosphorus was of such a magnitude that the child was in a negative balance in respect to nitrogen and phosphorus, and retained only 2 per cent of his ingested calcium. The high fecal phosphorus excretion resulted in a reversal of the normal fecal: urinary phosphorus ratio of $2: 3$ (16).

Following the "crisis" there was a diuresis, with a loss of $6.5 \mathrm{kgm}$. in weight and complete disappearance of edema. At the same time, the serum protein and calcium levels rose simultaneously to near normal values. The diuresis was accompanied by a remarkable outpouring of sodium, calcium, and phosphorus in the urine. The average daily urinary sodium excretion cluring the

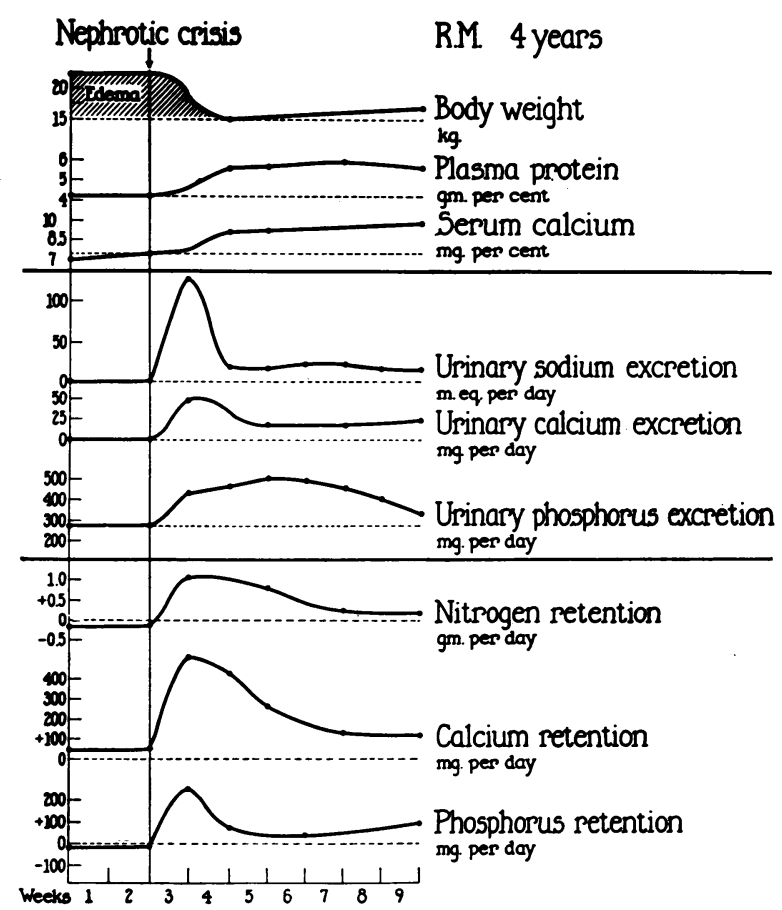

Fig. 3. A Graphic Representation of the Metabolic Events Occurring at the Time of a Nephrotic "Crisis" Associated with a Type IV Pneumococcal Bacteriemia in Patient R. M. 
2 weeks after the "crisis" was 60 m.eq. greater than the intake, and the average daily weight loss 450 grams. Since 450 grams of interstitial fluid contain 65 m.eq. of sodium, it is apparent that this patient's weight loss could be almost entirely accounted for by a loss of interstitial fluid.

Owing to the sharp decrease in fecal excretion, there was also a tremendous increase in total calcium retention, notwithstanding the marked increase in the urinary output of this element. The total retention of nitrogen and phosphorus was likewise greatly increased, and the fecal: urinary phosphorus ratio returned to normal (Table I). In this respect, the patient behaved like a child who, after a prolonged period of starvation, was again receiving an adequate diet. The rapid shift of calcium and phosphorus excretion from stool to urine, which would not be expected to occur during recovery from starvation, is probably a secondary result of the correction of the abnormal water retention in nephrosis. Apparently, the calcium and phosphorus contained in the edema fluid were in large measure washed out along with the sodium during the diuresis. After the edema had subsided, the urinary calcium excretion fell to low normal values which would be expected in the presence of a skeletal calcium deficiency.

The combination of low serum calcium concentration, extremely low urinary calcium excretion, and abnormally low calcium retention has been encountered in all the nephrotic children that have been studied, both by others (5) and by us. This combination appears to be characteristic of the disease. In case R. M. (Table I and Figure 3), all these abnormalities of calcium metabolism present before the "crisis" entirely disappeared after the "crisis," together with the clinical signs of nephrosis other than albuminuria. This occurrence adds to the evidence that the calcium abnormalities are a part of the nephrotic syndrome.

\section{DISCUSSION}

Three facts appear from the observations presented: $I$. The shafts of the bones showed rarefaction by $x$-ray examination, while, on the contrary, the density of the epiphyseal lines was relatively normal. II. Skeletal growth was normal, in so far as bone length and shape were concerned. III. The nephrotic children failed to retain calcium at a rate even remotely approaching the re- tention rates of normal children. In 2 of the 3 cases, fecal excretion of calcium almost exactly equaled calcium intake. Almost no calcium was excreted in the urine. Apparently, the renal retention was compensatory; without it, the calcium deficit of the organism would have been more severe.

The actual rates of calcium storage per $\mathrm{kgm}$. body weight for all our experimental subjects, including R. M. before and after his "crisis," have been calculated from the data in Table I and are presented in Table II. Additional data obtained in the case of S. G. after his dietary calcium had been more than doubled are also given in Table II. To compare graphically the annual rate of calcium storage of these children on their standard diets throughout the course of their illness with the annual rate of a normally growing child, as given by Leitch (17), Figure 4 has been constructed by assuming that the total annual increase in body calcium equals the average daily calcium retention per $\mathrm{kgm}$. ideal body weight $\times$ average annual body weight $\times 365$. The data for calculating the annual rate of calcium storage in the children with nephrosis were taken from Table II. Patient S. G. presents an extreme example of the total calcium deficit which can occur in these children over the course of time. His annual calcium storage rate shown in the graph between the ages of 9 and 11 years was calculated from the data obtained when his intake was 0.736 gram of calcium per day which is approximately the amount of calcium provided by the highprotein, low-salt diet employed in the treatment of nephrosis in this hospital. On this intake, S. G. retained $8 \mathrm{mgm}$. of calcium daily. At that rate, he would store only 2.85 grams of calcium in a year. When his intake was increased to 2.180 grams of calcium per day, the calcium retention rose to $220 \mathrm{mgm}$. per day (Table II), or 80 grams per year, as shown in the graph for the period between 11 and 12 years. Leitch found that an average of 120 grams was stored annually by a child of the same age. ${ }^{3}$

\footnotetext{
${ }^{3}$ Leitch's figures agree with those of Sherman (18) but are higher than others in the literature, notably those of Kinsman et al. (19), Duckworth (20), Shohl (21), and Macy (22). R. Q. and R. M., however, show deficient calcium storage by any published standard, and only S. G. on the high intake of 2 grams daily reaches
} 
TABLE II

Average daily calcium retention per kilogram ideal body weight in 3 children with nephrosis (including one convalescent after $a$ "nephrotic crisis") and one normal child

\begin{tabular}{|c|c|c|c|c|c|c|c|}
\hline \multirow{3}{*}{ Patient } & \multirow{3}{*}{ Date } & \multirow{3}{*}{$\begin{array}{l}\text { Actual } \\
\text { weight }\end{array}$} & \multirow{3}{*}{$\begin{array}{c}\text { Ideal weight } \\
\text { for height }\end{array}$} & \multicolumn{4}{|c|}{ Calcium } \\
\hline & & & & \multirow{2}{*}{ Intake } & \multirow{2}{*}{ Balance } & \multicolumn{2}{|c|}{ Retention } \\
\hline & & & & & & \begin{tabular}{|c|} 
Per $\mathbf{k g m}$. \\
ideal weight
\end{tabular} & $\begin{array}{c}\text { Percentage } \\
\text { of intake }\end{array}$ \\
\hline S. G. 11 yrs. & 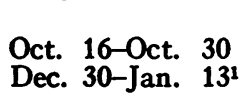 & $\begin{array}{l}\mathrm{kgm} . \\
26.7 \\
25.8\end{array}$ & $\begin{array}{l}k g m . \\
26.3 \\
26.3\end{array}$ & \begin{tabular}{|c} 
grams per day \\
0.736 \\
2.180
\end{tabular} & $\begin{array}{l}\text { grams per das } \\
+0.008 \\
+0.220\end{array}$ & $\mid \begin{array}{c}\text { grams per day } \\
0.0003 \\
0.008\end{array}$ & $\begin{array}{c}\text { per cent } \\
1 \\
10\end{array}$ \\
\hline R. Q. 9 yrs. & Feb. 3-Feb. 17 & 27.0 & 30.4 & 0.993 & +0.112 & 0.004 & 11 \\
\hline $\begin{array}{l}\text { R. M. } 4 \text { yrs. (Before "crisis") } \\
1 \text { week after "crisis"" } \\
4 \text { weeks after "crisis" }\end{array}$ & $\begin{array}{l}\text { Dec. 30-Jan. } 13 \\
\text { Feb. 24-Mar. } 10 \\
\text { Mar. 24-Mar. } 31\end{array}$ & $\begin{array}{l}22.0 \\
15.5 \\
15.2\end{array}$ & $\begin{array}{l}16.4 \\
16.4 \\
16.4\end{array}$ & $\begin{array}{l}0.823 \\
0.948 \\
0.948\end{array}$ & $\begin{array}{l}+0.015 \\
+0.484 \\
+0.215\end{array}$ & $\begin{array}{l}0.001 \\
0.030 \\
0.013\end{array}$ & $\begin{array}{r}2 \\
51 \\
22\end{array}$ \\
\hline J. P. 5 yrs. Normal & May 12-May 19 & 20.2 & 18.6 & 1.077 & +0.268 & 0.014 & 25 \\
\hline
\end{tabular}

17.5 grams of calcium lactate per day added to diet.

In spite of their deficient calcium retention, 2 of the nephrotic subjects, R. Q. and R. M., grew at a perfectly normal rate, as measured by the

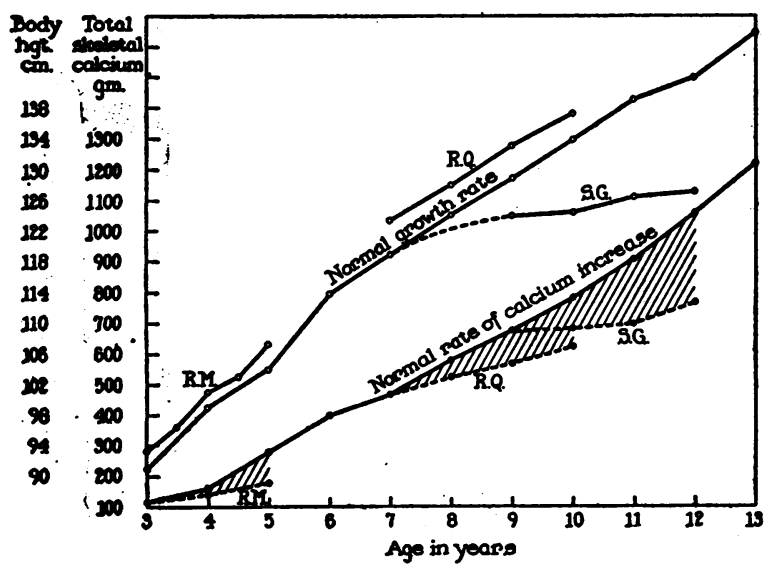

Fig. 4. Rate of Growth and Calcium Storage in Noryal Children and in 3 Children with Nephrosis, S. G.,* R. Q., and R. M., Throughout the Course of Their IllNess

Normal values taken from Leitch (17). Values for patients calculated from data in Table II.

* S. G.'s calcium storage rate during his 9 th and 10th years was calculated from the data obtained while he was on a daily intake of 0.736 gram of calcium; during his 11th year the data obtained while he was on a daily intake of 2.197 grams were used (see Table II).

the lower storage levels observed in normal children on half that intake.
Baldwin-Wood standards for height (23), during the entire period of their illness. S. G., the child who failed to grow normally, was the one whose urea clearance test and urine concentrating ability were diminished. ${ }^{4}$ All 3 children presented the same degree of skeletal decalcification. These facts are important in indicating that the decalcification is not the result of a generalized nutritional disturbance with failure to form new bone matrix, but rather an inability to retain calcium in the shafts even though it was deposited at the epiphyseal lines.

Of the foregoing facts, the following may be related in a direct sequence of cause and effect: (1) the excessive fecal loss of calcium, (2) the failure to retain calcium at a normal rate, and (3) the rarefaction of the shafts of the long bones. Two additional facts are of importance in describ-

4 In the 2 years since the completion of this study, patient S. G. has taken a sudden spurt in growth of $8 \mathrm{~cm}$. in contrast to a growth of only $4 \mathrm{~cm}$. in the 3 preceding years. At the same time, his $x$-rays indicate a much greater degree of skeletal calcification. This has taken place in spite of the fact that he is now suffering from chronic glomerular nephritis with approximately the same degree of renal impairment that he showed during the study. The only difference in his present condition is that he is no longer in the nephrotic stage and now has a normal serum protein and calcium level. He has not reached the stage of advanced renal failure with serious phosphorus retention and acidosis. 
ing the general picture of the disturbance of calcium metabolism in nephrosis: (1) normal growth of long bones and (2) apparently adequate calcification of the epiphyses.

The following interpretations have been made from these facts: (1) Bone matrix formation is normal. (2) Calcification of the shafts is incomplete because of a deficient supply of calcium. (3) Under conditions of general calcium deficit, the epiphyses of the growing bones are favored, with regard to calcium distribution, at the expense of the shafts.

\section{SUMMARY AND CONCLUSIONS}

I. The combination of generalized rarefaction of diaphyseal bone and relatively good calcification in the regions of epiphyseal growth has been a uniform x-ray finding in the children with nephrosis studied in this clinic. Most of these children have shown normal rates of bone growth and in none has there been any sign of rickets or other skeletal deformity.

II. The disturbances of calcium metabolism in nephrosis described by previous investigators have been found to be present also in the 3 nephrotic children who were the principal subjects of the present study. These disturbances are: (1) an abnormally low serum calcium concentration, (2) excretion of an abnormally great percentage of the ingested calcium in the stools, and (3) a virtual absence of calcium in the urine.

III. The excessive loss of calcium in the feces results in a rate of calcium storage far below normal for the growing child. Presumably this failure to store calcium at a normal rate leads to the skeletal decalcification demonstrable by $x$-ray. The presence of normal bone growth and relatively good epiphyseal calcification suggests that the available supply of calcium is distributed in the growing epiphyses in preference to the diaphyses.

IV. In one patient who underwent a sudden remission from his disease, the rapid disappearance of all clinical signs of nephrosis was accompanied by an equally prompt correction of the disturbances in calcium metabolism. This observation supports the view that the abnormal calcium metabolism is a part of the nephrotic syndrome.

\section{BIBLIOGRAPHY}

1. Epstein, A. A., Concerning the causation of edema in chronic parenchymatous nephritis; methods for its alleviation. Am. J. M. Sc., 1917, 154, 638.

2. Salvesen, H. A., and Linder, G. C., Observations on the inorganic bases and phosphates in relation to the protein of blood and other body fluids in Bright's disease and in heart failure. J. Biol. Chem., 1923, 58, 617.

3. Liu, S. H., The partition of serum calcium into diffusible and non-diffusible portions. Proc. Soc. Exper. Biol. and Med., 1926-27, 24, 817.

4. McLean, F. C., and Hastings, A. B., The state of calcium in the fluids of the body. I. The conditions affecting the ionization of calcium. J. Biol. Chem., 1935, 108, 285.

5. Boyd, G. L., Courtney, A. M., and MacLachan, I. F., The metabolism of salts in nephritis. I. Calcium and phosphorus. Am. J. Dis. Child., 1926, 32, 29.

6. Scriver, W. deM., Observations on the excretion of calcium in two cases of nephrosis treated with parathyroid extract. J. Clin. Invest., 1928, 6, 115.

7. Tisdall, F. F., and Kramer, B., Methods for the direct quantitative determination of sodium, potassium, calcium, and magnesium in urine and stools. J. Biol. Chem., 1921, 48, 1.

8. Van Slyke, D. D., and Sendroy, J., Jr., Gasometric determination of oxalic acid and calcium, and its application to serum analysis. J. Biol. Chem., 1929, 84, 217.

9. Nordbö, R., Magnesiumbestimmung mit der Oxinmethode im Ultrafiltrat von Blutserum und von Zentrifugenmilch. Skandinav. Arch. f. Physiol., 1939, 81, 258.

10. Butler, A. M., and Tuthill, E., An application of the uranyl zinc acetate method for determination of sodium in biological material. J. Biol. Chem., 1931, 93, 171.

11. Peters, J. P., and Van Slyke, D. D., Quantitative Clinical Chemistry. Vol. II. Methods. Williams and Wilkins Co., Baltimore, 1932. Reprinted June, 1943. Pages 520, 524 and 354-359.

12. Fiske, C. H., and Subarrow, Y., The colorimetric determination of phosphorus. J. Biol. Chem., 1925, 66, 375 .

13. Fiske, C. H., and Litarczek, G., The Determination of Potassium. In Folin, O., Laboratory Manual of Biological Chemistry, Ed. 5, D. Appleton-Century Co., New York, 1934, pages 239 and 353.

14. Van Slyke, D. D., and Folch, J., Manometric carbon determination. J. Biol. Chem., 1940, 136, 509.

15. Farr, L. E., Assimilation of protein by young children with the nephrotic syndrome. III. Effect of nephrotic crises on assimilation of nitrogen. Am. J. Dis. Child., 1939, 58, 939.

16. Myers, V. C., and Fine, M. S., The relative importance of the intestine and kidneys as excretory channels. Proc. Soc. Exper. Biol. and Med., 19181919, 16, 73. 
17. Leitch, I., The determination of the calcium requirements of man. Nutrition Abstr. and Rev., 1937, 6, 553.

18. Sherman, H. C., and Hawley, E., Calcium and phosphorus metabolism in childhood. J. Biol. Chem., 1922, 53, 375.

19. Kinsman, G., Sheldon, D., Jensen, E., Bernds, M., and Outhouse, J., The utilization of the calcium of milk by preschool children. J. Nutrition, 1939, 17, 429.

20. Duckworth, J., and Warnock, G. M., The magnesium requirements of man in relation to calcium requirements, with observations on the adequacy of diets in common use. Nutrition Abstr. and Rev., 1942, $12,167$.

21. Shohl, A. T., Mineral Metabolism. Am. Chem. Soc. Monograph Series, Reinhold Publishing Corp., New York, 1939.

22. Macy, I. G., Nutrition and Chemical Growth in Childhood. Vol. I. Charles C. Thomas, Springfield, Illinois, 1942.

23. Baldwin, B. T., and Wood, T. D., Weight-height-age tables in English units of American-born boys (girls) (clothed) of school age. Iowa Child Welfare Research Station, 1927. 